Arte, Individuo y Sociedad

ISSN: 1131-5598

https://dx.doi.org/10.5209/aris.70948

\title{
Arte, género y diseño en educación digital
}

Ricard Huerta (2020), Valencia, Universitat de València, 328 páginas. ISBN: 978-84-18329-13-5

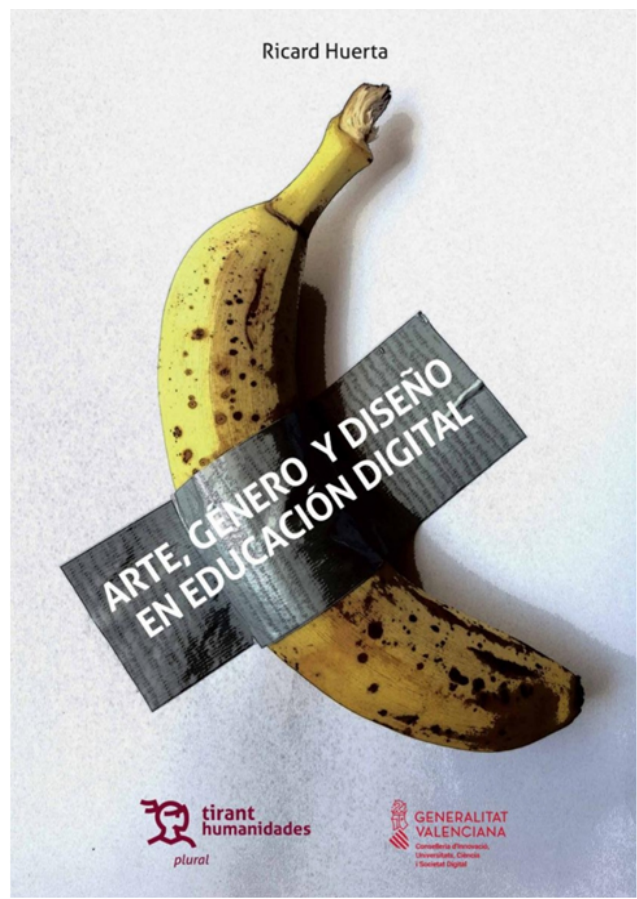

El concepto de arte es defendido por especialistas como D. Ricard Huerta para que su visibilidad en los currículos oficiales y en las prácticas de aula sea reconocida y efectiva. De hecho, se apuesta por las enseñanzas artísticas como medio para enseñar cuestiones de género y de diseño debido a las potencialidades que estas ofrecen como motor para el progreso social. Estos tres bloques son tratados en la obra a través del paradigma de la educación digital cada vez más vigente y actualizada, sobre todo debido al contexto histórico y sociológico que se atraviesa.

El libro queda dividido en siete capítulos. Los primeros tres capítulos se centran en indagar sobre los conceptos planteados en el título de la obra. En el primero, el autor responde a cuestiones sobre las potencialidades del arte en el universo digital como a través de los museos on-line que favorecen una mayor accesibilidad entre la audiencia, este es el caso de Museari. En el segundo, se definen conceptos 
relacionados con la tecnología y se reflexiona críticamente sobre estos. Se centra la atención, en el capítulo tercero, en el concepto de pedagogía aplicado a otros entornos educativos como el cine, la televisión y/o la fotografía.

Los siguientes tres capítulos (cuarto, quinto y sexto) se centran en conceptos como el de otredad, el de imagen como patrimonio colectivo y el de tipografía. En estos se realiza una aproximación a través de las obras de diferentes autores/ as. De hecho, gran parte de dicha creación queda recogida en formato imagen para acompañar al texto y generar un discurso visual que contribuye al entendimiento por parte de quien lee el libro. Asimismo, se rescata el séptimo capítulo. En este se responde a la cuestión "¿cómo nos está transformando el universo digital?" a través de la palabra de 20 profesionales de diferentes áreas con los que D. Ricard Huerta conversa, reflexiona y debate los cambios que genera la digitalización y cómo repercuten estos en la educación.

Con todo, se valoran las potencialidades de la obra entre todas aquellas personas que directa y/o indirectamente se relacionan con la educación, quienes deben iniciar una transición del plano analógico al digital. Así lo comparte el propio autor en la conclusión de su obra: "Esto acaba de empezar. La tecnología digital ha venido para quedarse, y se ha establecido en nuestras vidas en todos los sentidos, latiendo en todas las dimensiones posibles".

Vicente Monleón-Oliva Universitat de València vimono@alumni.uv.es https://orcid.org/0000-0001-8357-1316 